\title{
Considerations about Timing to Perform Elective Tracheostomies in Patients Hospitalized in COVID-19 Units
}

\author{
Juliano Mendes de Souza ${ }^{1}$, Nicholas Galat Ahumada², Hipolito Carraro Junior ${ }^{3}$ \\ ${ }^{1}$ Department of Surgery, Thoracic Surgery Unit, Hospital de Clínicas Complex, Federal University of Parana, Curitiba, Brazil \\ ${ }^{2}$ Department of Surgery, Head and Neck Surgery Unit, Hospital de Clínicas Complex, Federal University of Parana, Curitiba, \\ Brazil \\ ${ }^{3}$ Intensive Care Units, Hospital de Clínicas Complex, Federal University of Parana, Curitiba, Brazil \\ Email: julianomendes.dr@gmail.com
}

How to cite this paper: de Souza, J.M., Ahumada, N.G. and Carraro Junior, H. (2020) Considerations about Timing to Perform Elective Tracheostomies in Patients Hospitalized in COVID-19 Units. Surgical Science, 11, 237-241.

https://doi.org/10.4236/ss.2020.119026

Received: July 24, 2020

Accepted: September 8, 2020

Published: September 11, 2020

Copyright (c) 2020 by author(s) and Scientific Research Publishing Inc. This work is licensed under the Creative Commons Attribution International License (CC BY 4.0).

http://creativecommons.org/licenses/by/4.0/

\begin{abstract}
Since the beginning of the pandemic caused by the new Coronavirus (SARSCoV-2), critically ill patients care has been challenging. It is necessary to perform the best available practice and protect the health team, preserving human resources and rationalizing costs. Changes in tracheostomies institutional protocols are necessary according to each health care services reality. This is particular important in developing countries. The aim of this study is to establish a practical and sucint guideline to minimize controversies regarding the proper timing to perform elective tracheostomies in critically ill coronavirus infected patients.
\end{abstract}

\section{Keywords}

Tracheostomy, Intensive Care Units, Coronavirus Infections

\section{Introduction}

Since the announcement of the first cases of pneumonia due to an unknown cause in December 2019, with the establishment of a disease caused by the new Coronavirus (SARS-CoV-2), a pandemic has been installed with more than $3,000,000$ cases reported worldwide. Of these cases, about $17 \%$ develop the Acute Respiratory Distress Syndrome in different degrees of intensity. Care of these patients has become a challenge, mostly because is necessary to understand the clinical-epidemiological characteristics of the disease. And is an urgent premise to protect the health professionals involved and not exhaust the financial re- 
sources available for assistance [1] [2]. Tracheostomy is a routine procedure in patients requiring mechanical ventilation due to respiratory failure. It helps the airway hygiene, prevents trachea stenosis and facilitates weaning from mechanical ventilation [2]. Tracheostomy is not always benefit to patients. Half patients do not survive for more than one year after requiring a tracheostomy [3]. The coronavirus spreads through respiratory droplets and by direct contact with surfaces or objects used by infected people. In critical care facilities, aerosolizing procedures are the most dangerous way to contaminate health care team [4]. The viral detection in mucosal samples in most patients usually decreases after 11 days from viral initial exposure. As time goes by the infectivity also decreases [2]. Elective tracheostomy is usually performed from the seventh day from intubation, but it is also acceptable from 5 to 14 days [6]. The aim of this study is to establish a practical and sucint guideline regarding the proper timing to perform elective tracheostomies in COVID-19 infected patients.

\section{Methods}

An integrative review was done regarding the studies published during the Covid-19 pandemic. PubMed, Lilacs, Google Scholar and Scielo databases were used to search relacted articles. Only texts in english and portuguese were used. The terms used in the bibliographic search were "tracheostomy" and "coronavirus". The inclusion criteria were studies that discussed the safety procedures and timing to perform elective tracheostomies.

\section{Results and Discussion}

During the pandemic, the following considerations must be reinforced. Tracheostomy plays an important role in the weaning process of mechanical ventilation. There is a need to adapt the usual procedures during a COVID-19 Pandemic. The reality and availability of local staff and material resources are always taken into account when making decisions. Tracheostomy and post-procedure care expose the health team at risk of contamination. The decision to perform the tracheostomy must consider the best existing practice. A tracheostomy in patient COVID-19 may not always be beneficial [5] [6] [7] [8].

The majority of studies reviewed agreed that a multidisciplinary approach is mandatory to decide indications and ideal time to perform elective tracheostomies. A resume of these recommendations is on Table 1.

Due to the increased risk to contaminate the health care team working in COVID-19 units, several steps and check points must be observed during the tracheostomies. These essential check points are summaryzed in Table 2.

It is considered that patients affected by the critically stages of this disease need mechanical ventilation for a long time. The performance of elective tracheostomies in patients undergoing prolonged mechanical ventilation has benefits in terms of airway management, injury prevention and facilitating the weaning of the ventilator [1] [2] [5] [6]. 
Table 1. Ideal time to perform the procedure [1] [2] [5]-[10].

\section{Time to perform tracheostomy}

Tracheostomy should only be considered in patients who have shown a good evolution

Patients with ventilatory instability or need for high $\mathrm{FiO}_{2}$ are not candidates for tracheostomy

Patients who demonstrate poor prognosis are not candidates for tracheostomy

Patients who require a prone position for ventilation are not candidates for tracheostomy

Extubation attempts should be conservative, given the team's exposure and risk of contamination in new intubation

Tracheostomy should be considered after at least three attempts at weaning from mechanical ventilation, with the patient still intubated in an unsuccessful $\mathrm{T}$ tube ventilation in a period of 7 consecutive days

In cases of extubation failure requiring re-intubation, the reasons for the failure should be discussed and the tracheostomy considered

The ideal time for tracheostomy indication is between the $14^{\text {th }}$ and $21^{\text {st }}$ days of intubation

Obtaining the consent form for the procedure, from the in charge family member, remains mandatory

It is desirable that candidates for tracheostomy have a new PCR negative for Covid-19

$\mathrm{FiO}_{2}$ - Inspired fraction of oxygen, $\mathrm{PCR}-$ Polymerase Chain Reaction.

Table 2. Essential check points to perform the procedure [1] [2] [5]-[10].

Essential check points

There is no emergency response or any procedure without proper staff protection

Availability of complete personal protective equipment for all professionals involved in contact with the patient: masks type PFF2 or N95, face shield; long sleeve waterproof and disposable gown

The team must be composed of at least: surgeon, surgical assistant, nursing technician and anesthetist or intensive care physician (who will be responsible for the control of ventilation and management of the orotracheal tube)

Working and tested auxiliary surgical light

Working and tested electrocautery

Working and tested suction

Instruments for tracheostomy, tracheostomy cannulas with probable numbers (at least two cannulas of sequential numbers)

$100 \% \mathrm{FiO}_{2}$ and $5 \mathrm{~cm} \mathrm{H}_{2} \mathrm{O}$ PEEP ventilation prior to procedure

Checking the complete sealing of the orotracheal cannula cuff and positioning it distally to the tracheostomy site

Complete patient sedation using hypnotic agent, opioid and neuromuscular blocker (in charge of the anesthetist or intensive care physician)

No use of electrocautery on the trachea

Mechanical ventilation in PAUSE mode and clamped orotracheal tube for extubation

Tracheostomy cannula preferably already connected to the closed suction system and with a filter installed when introduced into the trachea

$\mathrm{FiO}_{2}$-Inspired fraction of oxygen, $\mathrm{PCR}-$ Polymerase Chain Reaction. 
Modifications of institutional protocols for performing elective tracheostomies are necessary, according to the proper realities of each assistance service, specially in developing countries [1] [2] [9].

Tracheostomies must be a safer procedure during the pandemic. Delay in indications protect pacients from unnecessary procedures and expose the team to a lesser risk of contamination due to a decreased virus count on patient airway [5] [6].

\section{Conclusion}

In order to preserve health care team and give chance of survival to patients able to recovery, it is mandatory to accomplish the best available practice to performing elective tracheostomies during the COVID-19 pandemic.

\section{Acknowledgements}

J.M.S. thanks to Fhilipe de Oliveira Prybicz and Allan Augusto Ferrari Ramos de Oliveira.

\section{Author Contributions}

All authors have read and approved the final version of the manuscript.

\section{Conflicts of Interest}

The authors declare no conflicts of interest regarding the publication of this paper.

\section{References}

[1] Smith, D., Montagne, J., Raices, M., Dietrich, A., Indalecio, C.B., Heras, M.L., et al. (2020) Tracheostomy in the Intensive Care Unit: Guidelines during COVID-19 Worldwide Pandemic. American Journal of Otolaryngology, 41, 102578. https://doi.org/10.1016/j.amjoto.2020.102578

[2] McGrath, B.A., Brenner, M.J., Warrillow, S.J., Pandian, V., Arora, A., Cameron, T.S., et al. (2020) Tracheostomy in the COVID-19 Era: Global and Multidisciplinary Guidance. The Lancet Respiratory Medicine. https://doi.org/10.1016/S2213-2600(20)30230-7

[3] Vargas, M., Sutherasan, Y., Brunetti, I., et al. (2018) Mortality and Long-Term Quality of Life after Percutaneous Tracheotomy in Intensive Care Unit: A Prospective Observational Study. Minerva Anestesiologica, 84, 1024-1031. https://doi.org/10.23736/S0375-9393.18.12133-X

[4] Tran, K., Cimon, K., Severn, M., Pessoa-Silva, C.L. and Conly, J. (2012) Aerosol Generating Procedures and Risk of Transmission of Acute Respiratory Infections to Healthcare Workers: A Systematic Review. PLoS One, 7, e35797. https://doi.org/10.1371/journal.pone.0035797

[5] Sommer, D.D., Engels, P.T., Weitzel, E.K., Khalili, S., Corsten, M., Tewfik, M.A., et al. (2020) Recommendations from the CSO-HNS Taskforce on Performance of Tracheotomy during the COVID-19 Pandemic. Version 2. Journal of OtolaryngologyHead \& Neck Surgery, 49, 23. https://doi.org/10.1186/s40463-020-00414-9 
[6] Takhar, T., Walker, A., Tricklebank, S., Wyncoll, D., Hart, N., Jacob, T., et al. (2020) Recommendation of a Practical Guideline for Safe Tracheostomy during the COVID19 Pandemic. European Archives of Oto-Rhino-Laryngology, 1-12. https://doi.org/10.1007/s00405-020-05993-X

[7] Yang, X., Yu, Y., Xu, J., Shu, H., Xia, J., Liu, H., et al. (2020) Clinical Course and Outcomes of Critically Ill Patients with SARS-CoV-2 Pneumonia in Wuhan, China: A Single-Centered, Retrospective, Observational Study. The Lancet Respiratory Medicine. https://doi.org/10.1016/S2213-2600(20)30079-5

[8] Tau, J.K., Khoo, M.L.-C. and Loh, W.S. (2020) Surgical Considerations for Tracheostomy during the COVID-19 Pandemic Lessons Learned from the Severe Acute Respiratory Syndrome Outbreak. JAMA Otolaryngology—Head \& Neck Surgery.

[9] Brazilian Society of Thoracic Surgery (2020) Recommendations of the Brazilian Society of Thoracic Surgery for Tracheostomy and Airway Management in Suspected or Confirmed Cases of COVID 19 Infection. https://www.sbct.org.br/2020/03/

[10] Brazilian Society of Head and Neck Surgery (2020) Recommendations of the Brazilian Society of Head and Neck Surgery for Tracheostomy and Airway Management in Suspected or Confirmed Cases of COVID-19. http://sbccp.org.br/wp-content/uploads/2020/03/RECOMENDACAO-TQT-COVI D19.pdf.pdf 